\title{
THE WIDER USES OF THE LANGUAGE LABORATORY
}

\author{
by Col. H. P. Montague
}

The expression "Language Laboratory" is not universally regarded as a suitable description of the function and potential of the facilities employed.

In so far as it is a laboratory, the expression has long been associated with the factual experimentation carried out in the sciences. The comparison with languages is only partial, and so far as experimentation is concerned, this is more likely to be of a general teaching value, of ultimate use to the student's learning patterns, than the more personal aspect of scientific experiment in laboratories essentially for the personal value of each student who carries out these experiments.

A distinction must, of course, be made between experimentation laid out for students at the college or university level, and the original experiments carried out by the scientist in the pursuit of knowledge. At this level there is, of course, a close parallel between the use of the laboratory by the scientist or the language teacher.

The implication of the word "language" in the expression "Language Laboratory" has tended to obscure the fact that the principles underlying the laboratory's use are just as applicable to a number of educational fields.

For that reason, it is well to establish a few of the first principles which make the language laboratory probably the most valuable teaching aid so far developed. It should be stressed at all times that the laboratory must be regarded as an aid, not a method independent of live teaching. The true basis of language study and teaching must be the relationship between teacher and student.

Leaving aside the many general advantages of the laboratory, the following would appear to be the basic principles which contribute to the value of this aid:

1. The student is able to concentrate on a lesson in complete isolation.

2. In private study he is able to check the quality of his own voice.

3. It is possible to control the speed of a lesson and to repeat when required.

4. It is possible to have a permanent record of important lectures or lessons for review or private study. 
Taking only those points as basic principles, it will be seen that language laboratory facilities can be used for students in almost any field. It is hard to envisage a branch of study where this technique could not be used. All that is required is the taped material which should be kept in the laboratory library.

From a purely educational point of view, the first of the points listed above is most worth expanding. There are many arguments against the classroom group as a teaching unit, especially when the numbers are large. It is the question of numbers which makes the distinction between teaching and lecturing. While there are many subjects which lend themselves to lecturing as a method of presentation, notably such subjects as history, the same cannot be said of languages. It must be accepted that conditions generally have led to classes being too large for true teaching to be allowed the maximum scope. This, in itself, provides a powerful argument for the use of language laboratory facilities for individual study to supplement live teaching.

There are many students who are inhibited in their reception of lessons taken in large groups. This is probably more true of language than of any other study. In fact, it is commonly held that English speakers, especially Englishmen, are particularly reluctant to speak foreign languages in the presence of others, at least in the learning stage.

If one pursued this point to its conclusion, one would have to acknowledge that many people of all ages who are retarded in any educational sense are retarded for this very reason. It may prove in the future to be a melancholy comment in educational history, that pupils have been neglected, ignored, or classed as subnormal for no better reason than that they are unsuited to learning in groups. It is to be hoped that the opportunities provided by the language laboratory type of facilities will, in the future, be more exploited in the education of this type of pupil.

To summarize, therefore, it would seem that the facilities of a language laboratory could be used:

1. By those students in particular who are slow in class instruction.

2. By those students who require encouragement to surmount current difficulties in their subjects. Such students would benefit in all fields, as in languages, by returning to an earlier lesson which provides review and also the satisfaction that comes from the assurance that a certain earlier lesson now seems much easier.

Against the above background, it would seem that all departments in a university have a clear use for these facilities. In particular, it would 
seem profitable for all teachers to observe which of their students seem most reluctant to absorb lessons in classes. Perhaps, most of all, teachers might consider the private approach to study offered by these facilities in all cases when progress is slower than seems justified by the willingness to learn or the general effort made by individual students. It is for consideration, indeed, whether all cases of poor progress should not be tested under these conditions to see whether individual study is not the real answer to slow progress.

It is strongly recommended that the point of the last sentence above should be subject in the future for experimentation in the laboratory in the interests of a study in the university, and in the wider interests of education.

\section{ABOUT THE AUTHOR:}

Col. Montague is assistant professor of languages at Queensborough Community College of the City University of New York.

\section{Notice of Change of Address}

To: James W. Dodge

Secretary, NALLD

Brown University

Box E

Providence, R. I. 02912

Former institution and address

Zip Code

Former mailing address

Zip Code

New institution and address

Zip Code

New mailing address

Zip Code

Effective date of change 